\title{
Peritoneal or mesenteric tumours revealing histiocytosis
}

Fleur Cohen-Aubart (D) ,,2 Irena Ungureanu, ${ }^{3,4}$ Jerome Razanamahery (i) , Frédéric Charlotte, ${ }^{6}$ Séverine Valmary-Degano, ${ }^{7}$ Zofia Hélias-Rodzewicz, ${ }^{3,8}$ Dominique Cazals-Hatem, ${ }^{9}$ Peggy Dartigues, ${ }^{10}$ Manuela Delage-Corre, ${ }^{11}$ Janick Selves, ${ }^{12}$ Patrick Tas, ${ }^{13}$ Sebastien Humbert, ${ }^{5}$ Alexandre Malakhia, ${ }^{14}$ Merja Kunnamo, ${ }^{15}$ Liana Veresezan, ${ }^{16}$ Chrystalla Prokopiou, ${ }^{17}$ Andreas Seeber, ${ }^{18,19}$ Abdellatif Tazi, ${ }^{20,21}$ Jean Donadieu, ${ }^{8,22}$ Olivier Lucidarme, ${ }^{23,24}$ Julien Haroche, ${ }^{1,25}$ Jean-François Emile (iD ${ }^{3,8}$

To cite: Cohen-Aubart F, Ungureanu I, Razanamahery J, et al. Peritoneal or mesenteric tumours revealing histiocytosis. BMJ Open Gastro 2021;8:e000622. doi:10.1136/ bmjgast-2021-000622

- Additional supplemental material is published online only. To view, please visit the journal online (http://dx.doi. org/10.1136/bmjgast-2021 000622).

FC-A, IU and JR contributed equally.

Received 10 February 2021

Revised 13 April 2021

Accepted 1 May 2021

\section{Check for updates}

(C) Author(s) (or their employer(s)) 2021. Re-use permitted under CC BY-NC. No commercial re-use. See rights and permissions. Published by BMJ.

For numbered affiliations see end of article.

Correspondence to Dr Jean-François Emile; jean-francois.emile@uvsq.fr

\section{ABSTRACT}

Objective Peritoneal or mesenteric tumours may correspond to several tumour types or tumour-like conditions, some of them being represented by histiocytosis. This rare condition often poses diagnostic difficulties that can lead to important time delay in targeted therapies. Our aim was to describe main features of histiocytoses with mesenteric localisation that can improve the diagnostic process.

Design We performed a retrospective study on 22 patients, whose peritoneal/mesenteric biopsies were infiltrated by histiocytes.

Results Abdominal pain was the revealing symptom in 10 cases, and 19 patients underwent surgical biopsies. The diagnosis of histiocytosis was proposed by initial pathologists in $41 \%$ of patients. The other initial diagnoses were inflammation $(n=7)$, sclerosing mesenteritis $(n=4)$ and liposarcoma $(n=1)$. The CD163/CD68+CD1ahistiocytes infiltrated subserosa and/or deeper adipose tissues in 16 and 14 cases, respectively. A BRAF $F^{V 600 E}$ mutation was detected within the biopsies in 11 cases, and two others were MAP2K1 mutated. The final diagnosis was histiocytosis in 18 patients, 15 of whom had Erdheim-Chester disease. The median diagnostic delay of histiocytosis was 9 months. Patients treated with BRAF or MEK inhibitors showed a partial response or a stable disease. One patient died soon after surgery, and five died by the progression of the disease.

Conclusion Diagnosis of masses arising in the mesentery should be carefully explored as one of the possibilities in histiocytosis. This diagnosis is frequently missed on mesenteric biopsies. Molecular biology for detecting the mutations in BRAF or in genes of the MAP kinase pathway is a critical diagnostic tool.

\section{INTRODUCTION AND OBJECTIVES}

Peritoneal or mesenteric tumours detected by imaging may correspond to carcinomatosis or sarcomatosis of a previously unsuspected tumour, or to a primitive mesothelioma. It may also reveal atypical proliferations such as abdominal desmoid tumour, inflammatory pseudotumour, infections
Summary box

What is already known about this subject?

- Only few case reports with peritoneal or mesenteric histiocytosis have been published as yet.

- Revealing symptoms, as well as the main clinical, pathological and molecular characteristics are not well described.

What are the new findings?

- Revealing symptoms of half of the patients was abdominal pain, and 19/22 patients underwent surgical biopsies.

- For half of them the first histopathological diagnosis was not histiocytosis (unspecific inflammation, sclerosing mesenteritis or liposarcoma).

- A BRAF or MAP2K1 mutation was detected in the majority of cases, and happens to be an important tool to achieve the diagnosis.

How might it impact on clinical practice in the foreseeable future?

- Gastroenterologists, digestive surgeons and oncologists will consider histiocytosis among the possible diagnoses of peritoneal/mesenteric tumours.

- Avoid surgical biopsy in some cases.

- Achieve the correct diagnosis, or achieve the final diagnosis in a shorter delay.

Propose efficient targeted therapies.

such as tuberculosis or be a manifestation of a systemic auto-immune or inflammatory disease, such as amyloidosis, Castleman disease or IgG4-related disease. Some of such rare conditions have been described as mesenteric panniculitis, mesenteric lipodystrophy or retractile mesenteritis before being gathered into a single entity: sclerosing mesenteritis. ${ }^{1}$ A few cases of histiocytosis associated with peritoneal/mesenteric tumours have been reported..$^{2-9}$

CT scans or MRI are good imaging modalities for the detection of peritoneal/ 


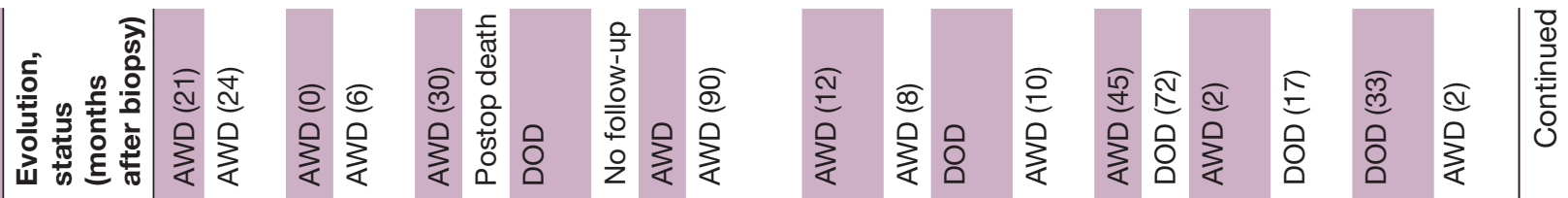

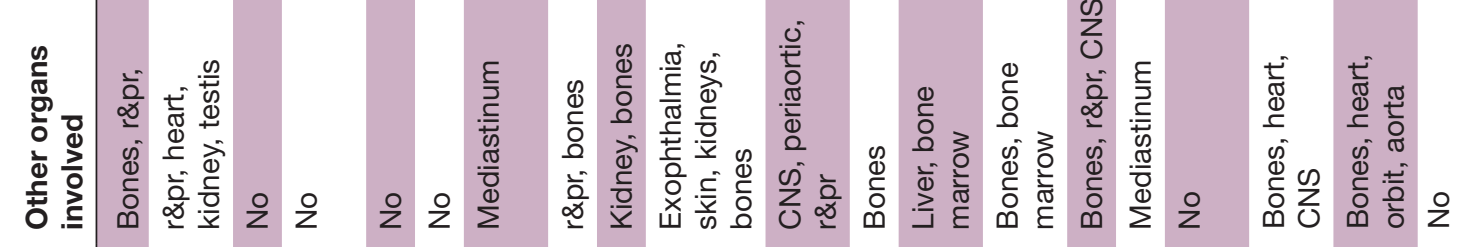

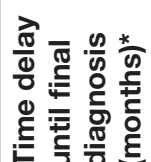

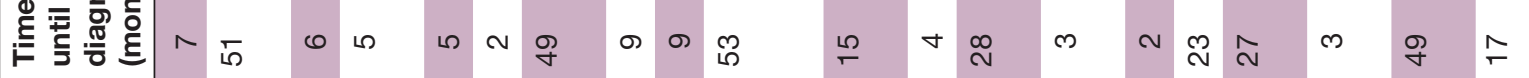

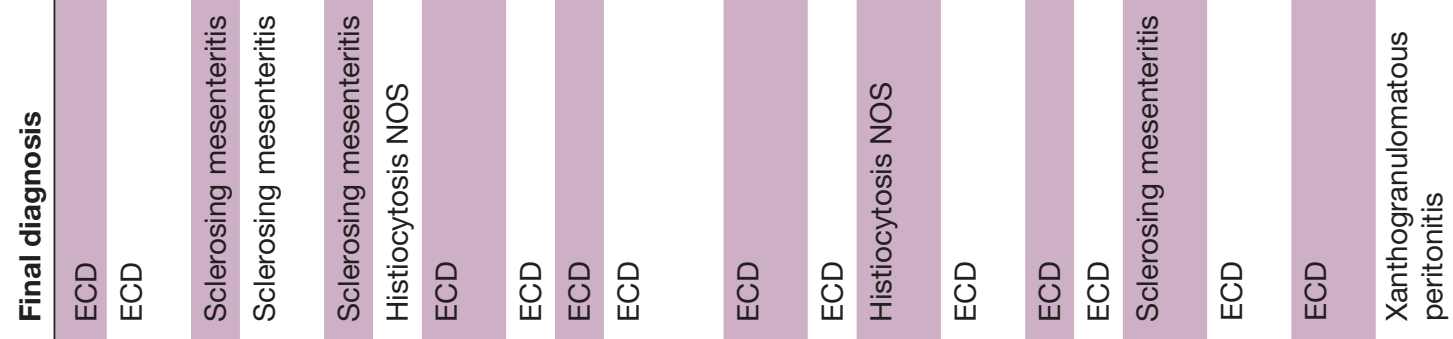

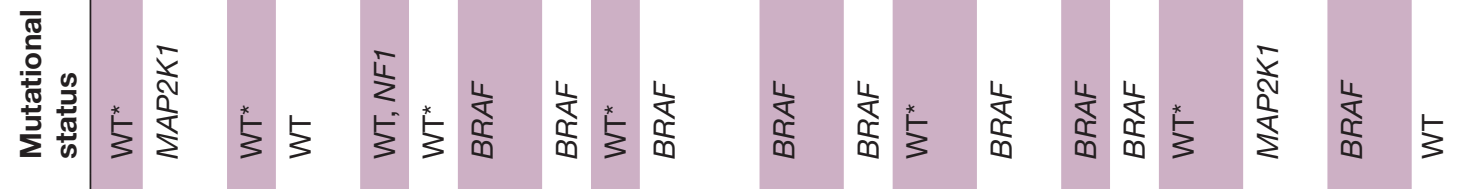

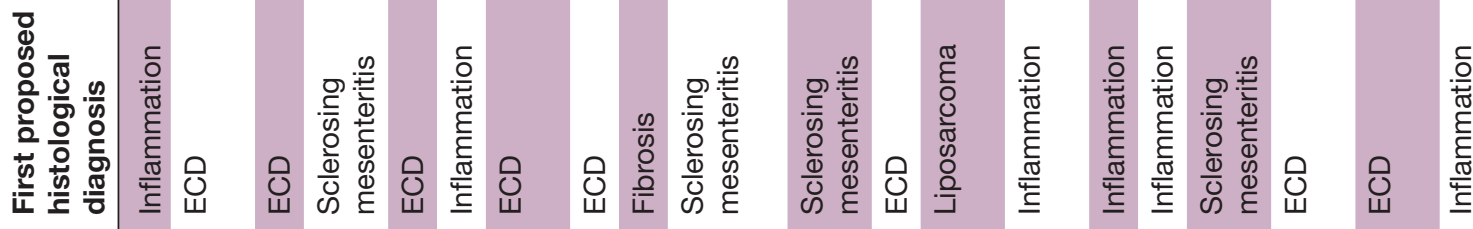

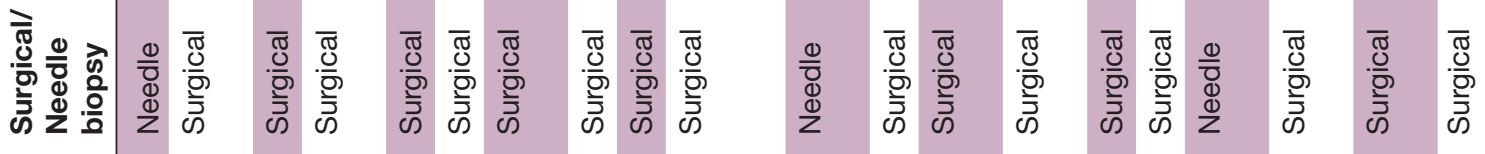

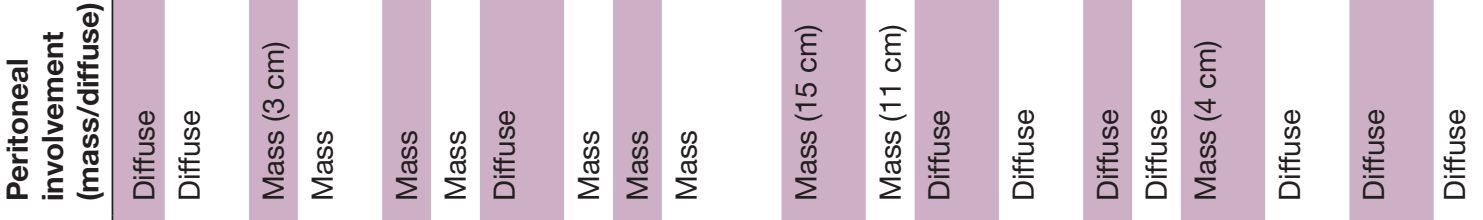

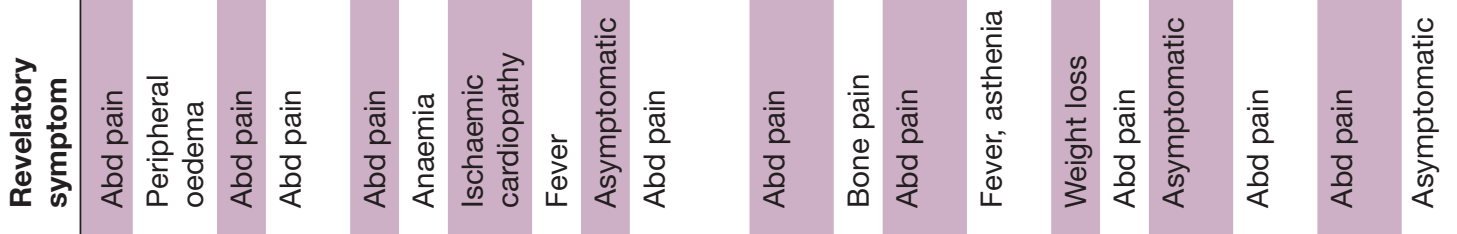

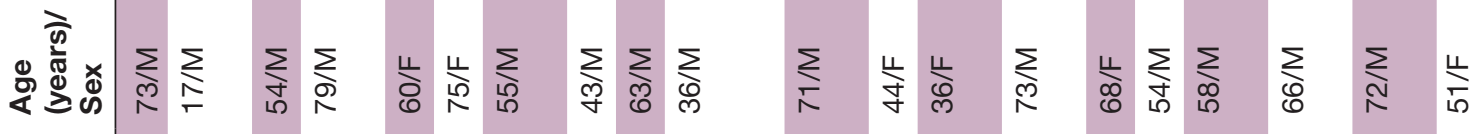
岳 


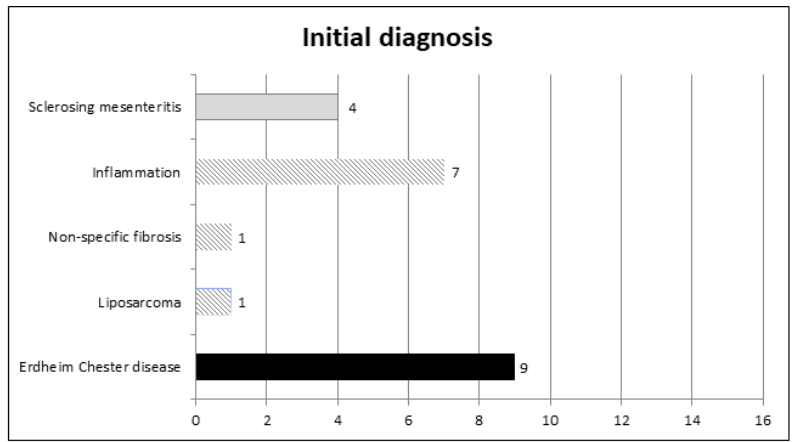

A

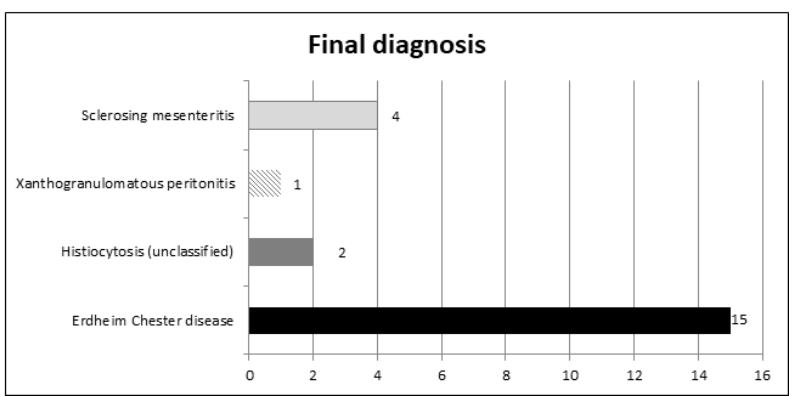

Figure 1 Initial and final diagnoses of patients within this cohort. Diagnosis of histiocytosis was proposed in 9/22 patients in initial pathology reports, and in 17 patients after central review.

mesenteric infiltrations. ${ }^{10}$ However, the final diagnosis of most of these conditions relies on histological examination of surgical or core needle biopsies. Histiocytes can be encountered in a wide range of diseases affecting peritoneum and mesentery, and thus the diagnosis of histiocytosis may be difficult in those biopsies. Conversely, inflammatory cells and fibrosis may be found with various degrees in biopsies of histiocytoses, leading to a major clue in the diagnosis of histiocytosis. Therefore, this diagnosis may be difficult for the pathologist who examines abdominal samples.

We reviewed a series of consecutive peritoneal/mesenteric biopsies referred for suspicion of histiocytosis. The objectives were to evaluate the difficulty and the delay of diagnosis and to better define clinical, histological and molecular features of these patients.

\section{DESIGN OF THE STUDY}

Cases were retrieved from the files of the Pathology Department of Ambroise-Paré Hospital, which is in charge of the central histological review and molecular analyses of the French Histiocytosis Network. Inclusion criteria were peritoneal or mesenteric biopsies received in the context of the French Network of Histiocytoses between April 2012 and April 2020. This means that the diagnosis of histiocytosis was discussed either initially or during follow-up and disease progression. In these cases of initial or late suspicion of histiocytosis, in France, the samples and slides are systematically referred to the Pathology Department of Ambroise-Paré Hospital for confirming or excluding this diagnosis. Clinical and 

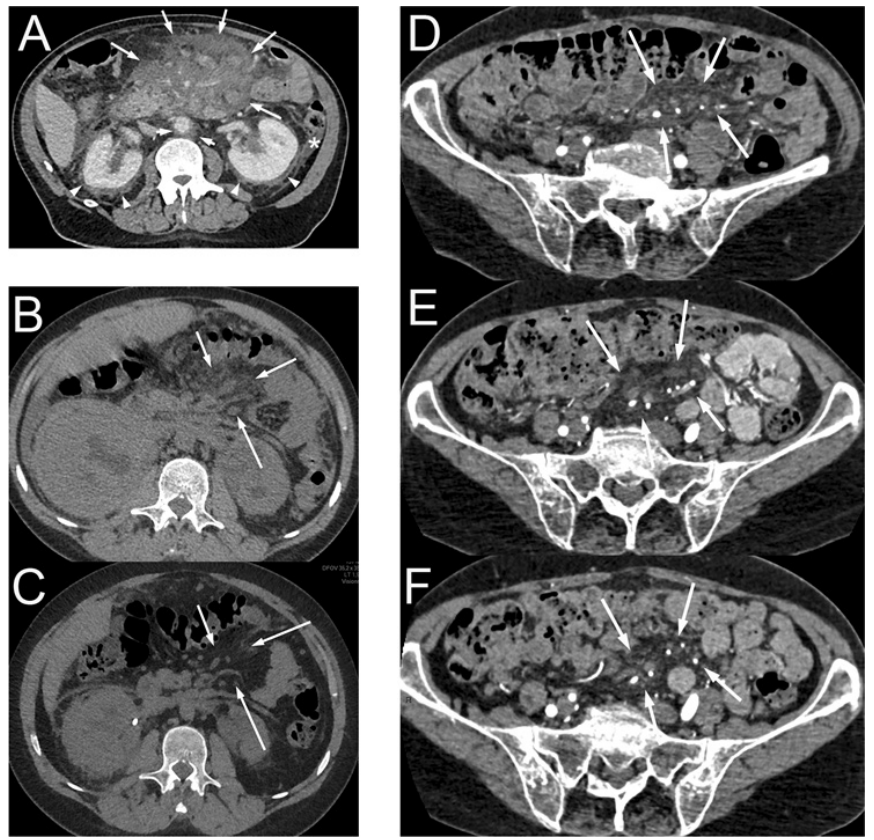

Figure 2 CT scan of patients with mesenteric involvement by histiocytosis. Patient \#11 (A) with mesenteric tumour (long arrows) surrounding mesenteric vessels, initially diagnosed as sclerosing mesenteritis. This patient had typical ErdheimChester lesions consisting in 'coated aorta' (short arrows) and 'hairy kidneys' (arrow heads). This patient also had intraperitoneal effusion in the parieto-colic area (star) and around the liver. Axial CT scan, contrast injection in portal phase. Patient \#2 with mesenteric infiltration (arrows) before (B), and with partial response after 4.5 months of treatment with trametinib (C). Axial CT scan, without contrast injection. Patient \#15 with mesenteric infiltration (arrows) in the pelvis, before (D) and after 7 months (E) and 39 months (F) of treatment with vemurafenib. Small lymph nodes were also present in this area. Axial CT scan, contrast injection.

follow-up information were obtained from patients' medical records by electronic means. All patients (except \#6 who died 2 days after surgery) had a clinical and imaging workup including ${ }^{18}$ F-fluorodeoxyglucose (FDG) positron emission tomography (PET) scan. All medical charts were centrally reviewed by two experimented clinicians (FC-A and JH) for retrieving the final diagnosis. For Erdheim-Chester disease (ECD) and other type of histiocytosis diagnosis, the international criteria were used for diagnosis of histiocytosis. ${ }^{11} 12$ ECD was confirmed when biopsy showed an infiltration with mononucleated CD163+CD1a- histiocytes, some of which with foamy cytoplasm, associated with either a gain of function mutation of $B R A F / M A P 2 K 1$ and/or with the presence of at least one typical ECD long bone, peri-renal or peri-aortic localisation.

Time delay was calculated as the time between the first symptom and the final diagnosis.

All biopsy samples (surgical or needle biopsies) were centrally reviewed by pathologists (IU, FG, J-FE). Immunohistochemistry was performed using Bond Max (Leica Biosystem, Newcastle, UK) with BOND Polymer Refine Detection Leica. Primary antibodies were CD163
(10D6, Leica), CD68 (514H12, Leica), CD1a (O10, Dako, Glostrup, Denmark), S100 (polyclonal, Dako) and phosphoERK (Erk 1/2, Cell Signaling, Beverly, USA).

Detection of somatic mutations was performed on DNA extracted from areas infiltrated with the highest percentage of histiocytes. The $B R A F^{V 600 E}$ mutation was detected by real time PCR, pyrosequencing or/and pddPCR as previously described. ${ }^{13} 14$ Cases without a $B R A F^{V 600 E}$ mutation were screened for other mutations in genes of the MAP kinase signalling pathway by targeted next-generation sequencing (NGS). For the targeted NGS, libraries were obtained using TruSeqCustom Amplicon Low Input kit (Illumina) with a custom panel of 76 genes of the MAP kinase pathway or frequently mutated in myeloid malignancies. ${ }^{15}$ Sequencing was performed on a Miseq sequencer (Illumina). Read alignment, variant calling and annotation were performed using GensearchNGS V.1.6.31 (PhenoSystems). The sensitivity was $2 \%$. All variants were checked using IGV software V.2.3.

\section{RESULTS}

Twenty-three peritoneal or mesenteric biopsies, corresponding to 23 patients, were retrieved. Among them, one case was excluded because of the lack of tumour block and of clinical data. The 22 remaining cases corresponded to $1.5 \%$ of 1499 samples with the diagnosis or suspicion of histiocytosis referred in Ambroise-Paré pathology centre during the period of study. These 1499 samples correspond to other organs such as bone $(27 \%)$, skin $(24 \%)$, perirenal (12\%), lung (4.2\%), etc.

The median age at the time of biopsy was 59 years, and female/male ratio was $6 / 16$. Ten patients $(45 \%)$ had abdominal pain as revelatory symptom (table 1). Three patients (14\%) underwent a percutaneous biopsy, while all others underwent surgery. The diagnosis proposed in the initial pathology report did not include histiocytosis in $13(59 \%)$ cases (figure 1A). Six patients (28\%) had a unique peritoneal infiltration, while clinical and radiological investigations revealed other organ involvement in the 17 remaining cases (table 1). Imaging revealed (figure 2) that the lesions presented either as a mesenteric mass $(n=11)$ or as multinodular/diffuse peritoneal infiltration $(\mathrm{n}=11)$.

All samples were infiltrated by mononucleated histiocytes, which had a foamy cytoplasm in the majority $(18 / 22,82 \%)$ of cases (table 2$)$. Histiocytes with eosinophilic cytoplasm were also present in 13 cases. (figure 3). The infiltration was superficial (ie, close to the serosa) in most $(16 / 20,80 \%)$ cases and deep (ie, infiltrating the adipose tissue of the omentum or the mesentery) in $14 / 20(70 \%)$ cases (figure 3$)$. In all cases, the phenotype was positive for CD163 (figure 2) and/or CD68 and negative for CD1a. Only 4/20 (20\%) cases were S100 positive.

A $B R A F^{V 600 E}$ mutation was detected in $11(50 \%)$ patients, whereas 2 had a $M A P 2 K 1$ gain-of-function mutation (p.(Gln56Pro) and p.(Lys57Asn)). Six of these mutated 
Table 2 Histological and immunohistochemical characteristics

\begin{tabular}{|c|c|c|c|c|c|c|c|}
\hline Case no. & Fibrosis & $\begin{array}{l}\text { Distribution of } \\
\text { macrophages }\end{array}$ & $\begin{array}{l}\text { Density of } \\
\text { histiocytes }\end{array}$ & $\begin{array}{l}\text { Cytoplasm of } \\
\text { macrophages }\end{array}$ & $\begin{array}{l}\text { Nuclei of } \\
\text { macrophages }\end{array}$ & $\begin{array}{l}\text { Giant } \\
\text { cells }\end{array}$ & Phenotype \\
\hline 1 & No & Superficial & Low & Foamy & $\begin{array}{l}\text { Fine chromatin, } \\
\text { nucleolated }\end{array}$ & Yes & $\begin{array}{l}\text { S100 } \\
\text { pERK }^{+} \mathrm{CD}^{+}{ }^{+}{ }^{+}, \mathrm{CD}^{-} \mathrm{a}^{-}\end{array}$ \\
\hline 2 & No & Superficial & Low & Eosinophil & Heterogenous & Yes & $\begin{array}{l}\mathrm{S} 100^{-}, \mathrm{CD}^{2} 63^{+}, \mathrm{CD}^{+}{ }^{+}, \\
\mathrm{CD}^{-} \mathrm{a}^{-}, \mathrm{pERK}^{+}\end{array}$ \\
\hline 3 & Yes & $\begin{array}{l}\text { Superficial and } \\
\text { deep }\end{array}$ & Moderate & Foamy & Small dense & No & $\begin{array}{l}\mathrm{S}^{100^{-}}, \mathrm{CD}^{2} 63^{+}, \mathrm{CD}^{+}{ }^{+}, \\
\mathrm{CD}^{-} \mathrm{a}^{-}, \mathrm{pERK}^{-}\end{array}$ \\
\hline 5 & No & Superficial & High & Foamy & Small dense & No & $\begin{array}{l}\mathrm{CD}^{2} 63^{+}, \mathrm{CD}^{+} 8^{+}, \mathrm{CD}^{-} \mathrm{a}^{-} \text {, } \\
\text { pERK }^{-}\end{array}$ \\
\hline 6 & No & $\begin{array}{l}\text { Superficial and } \\
\text { deep }\end{array}$ & High & Eosinophil & $\begin{array}{l}\text { Small dense, } \\
\text { folded }\end{array}$ & Yes & $\begin{array}{l}\mathrm{S} 100^{-}, \mathrm{CD}^{+}, \mathrm{CD}^{-} \mathrm{a}^{-} \\
\mathrm{pERK}^{+}\end{array}$ \\
\hline 9 & No & Superficial & Low & Eosinophil & Heterogenous & Yes & $\begin{array}{l}\mathrm{S} 100^{+}, \mathrm{CD}_{163}{ }^{+}, \mathrm{CD}^{-} \mathrm{a}^{-} \\
\mathrm{pERK}^{+}\end{array}$ \\
\hline 10 & Yes & $\begin{array}{l}\text { Superficial and } \\
\text { deep }\end{array}$ & Moderate & Foamy & Heterogenous & Yes & $\mathrm{S} 100^{-}, \mathrm{CD} 8^{+}, \mathrm{CD} 1 \mathrm{a}^{-}$ \\
\hline 11 & Yes & $\begin{array}{l}\text { NA (small } \\
\text { sample) }\end{array}$ & Low & Foamy+eosinophil & $\begin{array}{l}\text { Fine chromatin, } \\
\text { nucleolated }\end{array}$ & No & $\mathrm{CD} 163^{+}, \mathrm{CD}^{-} \mathrm{a}^{-}$ \\
\hline 12 & No & $\begin{array}{l}\text { Superficial and } \\
\text { deep }\end{array}$ & High & Foamy & Small dense & No & $\mathrm{CD} 163^{+}, \mathrm{CD} 8^{+}, \mathrm{CD}^{-} \mathrm{a}^{-}$ \\
\hline 13 & No & $\begin{array}{l}\text { Superficial and } \\
\text { deep }\end{array}$ & High & Foamy & Pleomorphic & Yes & $\begin{array}{l}\mathrm{S} 100^{-}, \mathrm{CD}^{2} 63^{+}, \mathrm{CD}^{+} 8^{+} \\
\mathrm{CD}^{-} \mathrm{a}^{-}, \mathrm{pERK}^{-}\end{array}$ \\
\hline 17 & Yes & $\begin{array}{l}\text { NA (small } \\
\text { sample) }\end{array}$ & High & Foamy & Small dense & No & $\begin{array}{l}\mathrm{S} 100^{-}, \mathrm{CD}^{2} 63^{+}, \mathrm{CD}^{+}{ }^{+}, \\
\mathrm{CD}^{-} \mathrm{a}^{-}\end{array}$ \\
\hline 18 & Yes & Deep & Low & Eosinophil & $\begin{array}{l}\text { Fine chromatin, } \\
\text { nucleolated }\end{array}$ & Yes & $\begin{array}{l}\mathrm{S}^{100^{+}}, \mathrm{CD} 163^{+}, \mathrm{CD}^{+}{ }^{+}, \\
\mathrm{CD}^{2} \mathrm{a}^{-}, \mathrm{pERK}^{+}\end{array}$ \\
\hline 19 & Yes & Deep & Moderate & Foamy+eosinophil & $\begin{array}{l}\text { Fine chromatin, } \\
\text { nucleolated }\end{array}$ & Yes & $\mathrm{S} 100^{-}, \mathrm{CD} 68^{+}, \mathrm{CD}^{-} \mathrm{a}^{-}$ \\
\hline 20 & No & Deep & High & Foamy & Heterogenous & No & $\begin{array}{l}\mathrm{S} 100^{-}, \mathrm{CD}^{2} 63^{+}, \mathrm{CD}^{+}{ }^{+}, \\
\mathrm{CD}^{-} \mathrm{a}^{-}, \mathrm{pERK}^{+}\end{array}$ \\
\hline 21 & Yes & $\begin{array}{l}\text { Superficial and } \\
\text { deep }\end{array}$ & Moderate & Foamy+eosinophil & Heterogenous & No & $\begin{array}{l}\mathrm{S}^{100^{-}}, \mathrm{CD}^{-} 63^{+}, \mathrm{CD}^{+} 8^{+} \\
\mathrm{CD}^{-} \mathrm{a}^{-}, \mathrm{pERK}^{+}\end{array}$ \\
\hline 22 & No & $\begin{array}{l}\text { Superficial and } \\
\text { deep }\end{array}$ & Moderate & Foamy+eosinophil & Heterogenous & Yes & $\begin{array}{l}\mathrm{S}_{100^{+}}, \mathrm{CD}_{163}{ }^{+}, \mathrm{CD}^{+}, \\
\mathrm{CD}^{+} \mathrm{a}^{-}, \mathrm{pERK}^{+}\end{array}$ \\
\hline
\end{tabular}

${ }^{*}$ Cytosteatonecrosis associated.

NA, not analysable.

cases expressed phosphoERK (figure 2), corresponding to an activation of the RAS-ERK pathway, and one was negative. For three patients, an extensive molecular analysis did not reveal any mutation within the MAP kinase pathway, one of whom was positive for phosphoERK. For the six other patients, real-time PCR did not reveal a mutation in the codon V600 of $B R A F$, but the amount and/or quality of available DNA were too low for further analyses using more sensitive methods on V600, or targeting other loci of $B R A F$ and other genes of the MAP kinase pathway. Three of these latter patients expressed 


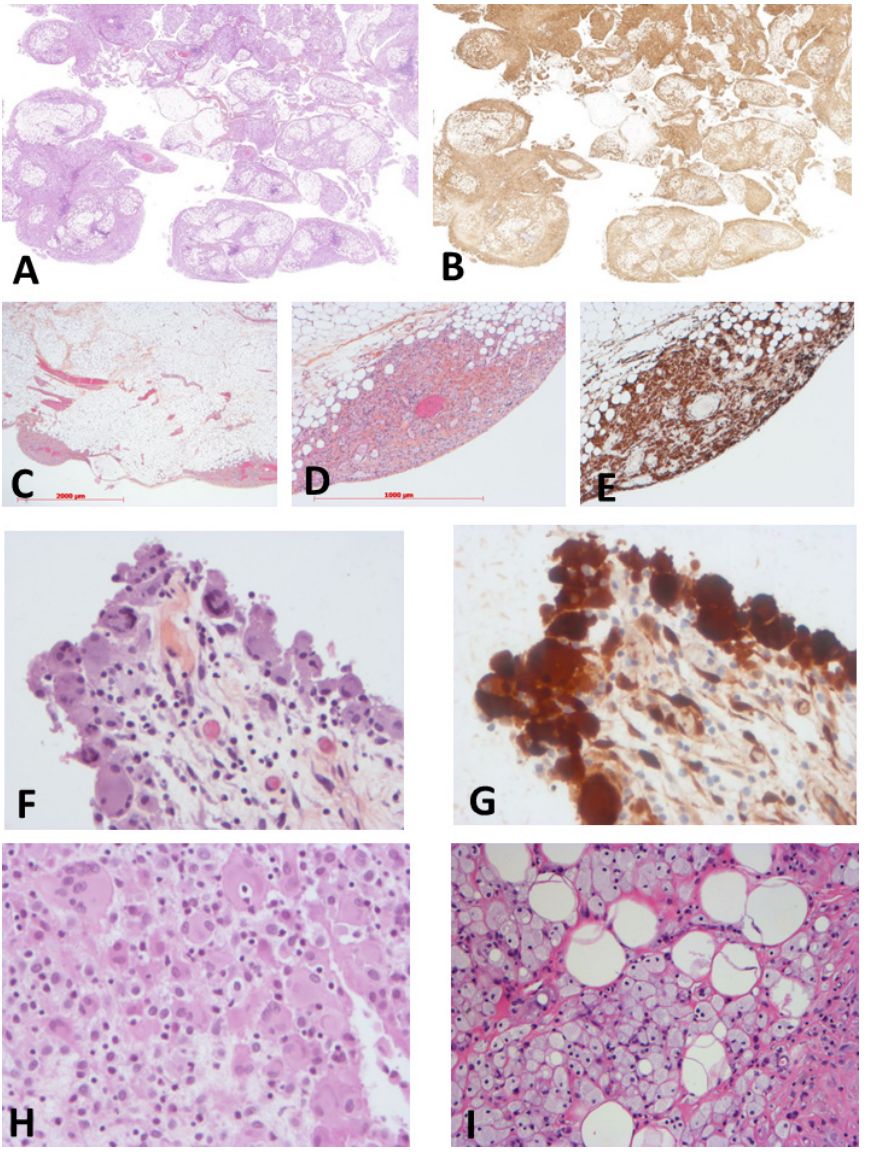

Figure 3 Histology of the patients with mesenteric involvement by histiocytosis. Low magnification showing diffuse, mainly superficial, involvement of epiploon by histiocytosis (patient \#13, H\&E ×1 (A) and CD163 ×1 (B)). Patchy superficial involvement of epiploon by histiocytosis (patient \#22, H\&E ×12 (C), H\&E ×40 (D) and CD163 ×40 (E)). Diffuse superficial involvement of serosa by eosinophilic histiocytes (patient \#9, H\&E ×200 (F), phosphoERK ×200 (G)). Infiltration by eosinophilic $(\mathrm{H})$ or foamy $(\mathrm{I})$ histiocytes (patient \#2, H\&E ×200 (H), patient \#10, H\&E ×40 (I)).

phosphoERK, demonstrating a strong activation of this cell signalling pathway.

The final diagnosis of the disease was ECD in 15 patients, and histiocytosis not otherwise specified (NOS) for 2 additional patients (figure 1B). For patient \#13, with final diagnosis of histiocytosis NOS, malignant histiocytosis could not be established on histology, because of a low mitotic activity and low Ki67 index; however, this patient was resistant to treatments and finally deceased from disease progression. The median delay between the biopsy and the final diagnosis of histiocytosis was 9 months.

Regarding the clinical evolution, one patient died 2 days after surgery (\#6), and five died from disease progression (\#7, \#13, \#16, \#18, \#19). Among patients with ECD, five received pegylated interferon $(\# 5, \# 7, \# 10$, \#14, \#16), six were treated with vemurafenib, a BRAF inhibitor (\#11, \#12, \#15, \#19, \#21, \#22), four received cobimetinib, a MEK inhibitor (\#1, \#2, \#15, \#22) and two are included in COBRAH (a blinded clinical phase II trial randomising placebo vs a MEK inhibitor) (\#5, \#9). All patients treated with vemurafenib showed a partial response (figure 2), and patients treated with MEK inhibitor yielded a partial response or a stable disease.

\section{DISCUSSION}

Herein, we have reported a series of 22 patients who underwent peritoneal/mesenteric surgical or percutaneous biopsies mainly infiltrated by histiocytes. In the majority of cases $(59 \%)$, the diagnosis of histiocytosis was not suspected before surgery. It was neither proposed nor discussed in the initial pathology report. However, the diagnosis of histiocytosis was finally achieved in 17 cases (77\%), 15 of whom correspond to ECD. The presence of a mutation activating the MAP kinase pathway and/or the detection of extraperitoneal/mesenteric localisations were very helpful to establish the final diagnosis. The median delay between the first symptom and diagnosis was 9 months (range $2-49$ months). The median age and disease extension were similar to those described in the largest series of patients with ECD. ${ }^{16}$

Single cases of histiocytosis with predominant peritoneal or mesenteric involvement have already been reported. Most of them corresponded to ECD and some to RDD. ${ }^{2-1017}$ Rare cases of reactive histiocytosis have also been reported, such as crystal storing histiocytosis and nodular histiocytic aggregate of the omentum. ${ }^{18-20}$ As for our patients, in most of these cases the diagnosis of histiocytosis was not initially suspected. Our large series allows to define the main characteristics of these abdominal histiocytic diseases.

Histiocytes were either foamy or with eosinophilic cytoplasm, sometimes associated with Touton cells. The density of histiocytes (low, moderate or high) showed no correlation with symptoms claimed by the patients. Despite the low number of needle biopsies, we suspect that they can lead to diagnosis in abdominal masses, but surgery should be proposed in cases with diffuse peritoneal infiltration. Molecular analysis revealed BRAF or $M A P 2 K 1$ mutations in $59 \%$ of patients, and was helpful to confirm diagnosis in most cases. These gain-of-function mutations are responsible for a constitutive activation of the MAP kinase signalling pathway, and are present in the majority of patients with ECD. ${ }^{14-21}$

Analysing this series of patients according to initial diagnoses might be helpful to avoid future misdiagnoses and to shorten diagnostic workup of forthcoming patients. A first group of four patients (\#4, \#10, \#11, \#17) were initially diagnosed as sclerosing mesenteritis, two of whom $(\# 10, \# 11)$ were finally diagnosed with ECD with typical involvement of long bones, retroperitoneum, skin and/or orbits. The two other patients (\#04, \#17) were finally confirmed as sclerosing mesenteritis, since no other organ involvement was present and no mutation was detected. Sclerosing mesenteritis (or mesenteric panniculitis, mesenteric lipodystrophy or retractile mesenteritis) is a rare condition that presents symptoms 

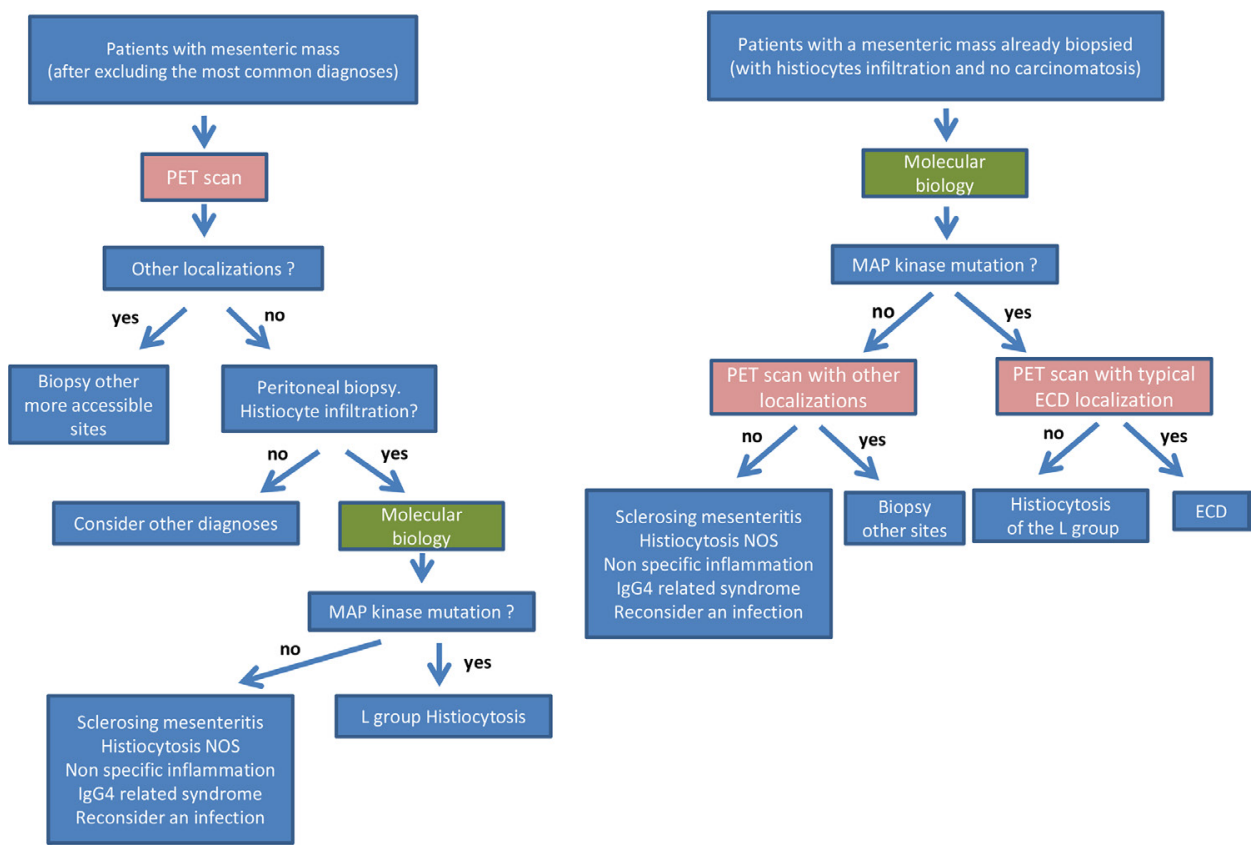

Figure 4 Recommendations for diagnostic process in patients with mesenteric mass of unknown aetiology.

associated with an abdominal mass. Up to $5.7 \%$ of cases are associated with autoimmune conditions such as hyper-IgG4 syndrome or lupus. Half of the patients do not require specific treatment. ${ }^{22}{ }^{23}$ In a recently proposed flow diagram of initial workup for sclerosing panniculitis, a PET scan was recommended only for patients with lymph nodes $>10 \mathrm{~mm}$, in order to exclude lymphomas. ${ }^{24}$ Alexiou et al reported a woman aged 56 years diagnosed with a sclerosing mesenteritis 8 years before, who presented with ECD and died a few weeks later from central nervous system involvement. ${ }^{3}$ Similarly, Moore et al described another patient with sclerosing mesenteritis, who presented 1 year postsurgery with exophthalmos; a full skeletal assessment was performed which revealed ECD. ${ }^{2}$ Our data and the previously published cases suggest that full body FDG-PET scan should be proposed to all patients with suspected sclerosing mesenteritis, especially when blood examination shows abnormalities suggestive for myeloproliferative neoplasms.

A second group of seven other patients were diagnosed as inflammation of the peritoneum (\#1, \#6, \#14, \#15, \#16, \#20, \#21). Five of them happened to have ECD (\#1, \#14, \#15, \#16, \#21), and another one had histiocytosis NOS (\#06). Patient \#16 underwent 16 successive frozen sections during laparotomy, since a peritoneal carcinomatosis was suspected but could not be confirmed. Finally, a third group of nine other patients were suspected with ECD since the beginning (\#2, \#3, \#5, \#7, \#8, \#12, \#18, \#19, \#22), and samples were sent to Ambroise-Paré Pathology Department for confirmation and/or for molecular analyses. Two out of these nine patients (\#3, \#5) were finally classified as sclerosing mesenteritis, confirming the difficult differential diagnosis between ECD and sclerosing mesenteritis, in the absence of extra-abdominal involvement and of a mutation activating the MAP kinase pathway. The major differences between diagnoses initially suspected and finally achieved, and the long delay to obtain this diagnosis, urged us to propose some recommendations for diagnostic process (figure 4).

The present paper has some limitations. It is a retrospective series and all samples were referred to our centre because of the suspicion of histiocytosis. Therefore, the proportion of sclerosing panniculitis which finally happened to be ECD is obviously overestimated. Similarly, a diffuse infiltration within the peritoneum by histiocytes may be related to several other aetiologies, including infections or tumours, and such cases were not referred to the French Histiocytosis Network. ${ }^{20}{ }^{25}$ By contrast, the proportion of ECD patients with peritoneal or mesenteric involvement (1.53\% of samples referred for suspicion of histiocytosis to the Ambroise-Paré Pathology Department) is obviously underestimated. Indeed, ECD usually involves other organs which are more accessible to fine needle biopsy. In a prospective study of 61 patients with extensive and standardised evaluation of disease extension, four $(6.6 \%)$ patients had an infiltration of the mesentery, of whom one was diagnosed on a mesenteric biopsy. ${ }^{26}$ However, a diffuse infiltration of the peritoneum with nodules $<5 \mathrm{~mm}$ may be undetectable with CT scan. The strength of our study is mainly based on a high number of cases contrasting with the published single case reports. Furthermore, all cases underwent phenotypic and molecular analyses. This allows us to draw conclusions based on different patterns that we observed. Several treatments have been used for patients with ECD and sclerosing mesenteritis (online supplemental table $1)$. In the present series, targeted therapies of ECD with either BRAF or MEK inhibitors induced partial responses in the majority of patients. 


\section{CONCLUSION}

This large retrospective series shows that abdominal pain and peritoneal or mesenteric tumours may reveal or be associated with histiocytosis. We emphasise the fact that histiocytosis is a rare diagnosis to be made, but in those cases where the most common diagnoses for a mesenteric mass have been excluded, histiocytosis is a possibility to take into consideration. We suggest that a PET scan may ease this process of diagnosis by revealing secondary localisation of histiocytosis. The majority of our patients were initially misdiagnosed and there was an important time delay. Molecular analysis is a major diagnostic tool to confirm the diagnosis. Once the diagnosis of ECD is achieved, targeted therapies may be highly efficient even in those cases with peritoneal localisation.

\section{Author affiliations}

${ }^{1}$ Sorbonne University, Paris, Île-de-France, France

${ }^{2}$ Service de Médecine Interne et Centre National de Référence Maladies

Systémiques Rares et Histiocytoses, University Hospital Pitié Salpêtrière, Paris, Île-de-France, France

${ }^{3}$ Department of Pathology, Hôpital Ambroise-Pare, Boulogne-Billancourt, Île-deFrance, France

${ }^{4}$ Department of Pathology, University Emergency Hospital Bucharest, Bucharest, Romania

${ }^{5}$ Department of Internal Medicine and Clinical Immunology, University Hospital Centre Dijon, Dijon, France

${ }^{6}$ Department of Pathology, University Hospital Pitié Salpêtrière, Paris, Île-de-France, France

${ }^{7}$ Institute for Advanced Biosciences, Inserm U 1209, CNRS UMR 5309, University Grenoble Alpes, Grenoble, Rhône-Alpes, France

${ }^{8}$ EA4340-BECCOH, Versailles Saint-Quentin-en-Yvelines University, Versailles, Îlede-France, France

${ }^{9}$ Department of Pathology, Hopital Beaujon, Clichy, France

${ }^{10}$ Department of Pathology, Gustave Roussy Institute, Villejuif, Île-de-France, France

${ }^{11}$ Department of Pathology, CHU Limoges, Limoges, Limousin, France

${ }^{12}$ Department of Pathology, Institut Universitaire du Cancer Toulouse Oncopole,

Toulouse, Occitanie, France

${ }^{13}$ Department of Pathology, CHU Pontchaillou, Rennes, Bretagne, France

${ }^{14}$ Department of Radiology, University Hospital Centre Besancon, Besancon, France

${ }^{15}$ Department of Medicine, Central Finland Central Hospital, Jyvaskyla, Central

Finland, Finland

${ }^{16}$ Department of Pathology, Centre Henri Becquerel, Rouen, Haute-Normandie, France

${ }^{17}$ Limassol General Hospital, Lemesos, Cyprus

${ }^{18}$ Medical University of Innsbruck, Innsbruck, Austria

${ }^{19}$ Department of Hematology and Oncology, Comprehensive Cancer Center Innsbruck, Innsbruck, Austria

${ }^{20}$ Centre National de Référence des Histiocytoses, Department of Pneumology, Hospital Saint-Louis, Paris, île-de-France, France

${ }^{21}$ FR-75006, Université de Paris, Paris, Île-de-France, France

${ }^{22}$ Department of Pediatric Hematology and Oncology, Centre de Référence des

Histiocytoses, Hôpital Armand-Trousseau, Paris, île-de-France, France

${ }^{23}$ Department of Radiology, University Hospital Pitié Salpêtrière, Paris, Île-deFrance, France

${ }^{24}$ CNRS, INSERM, Laboratoire d'Imagerie Biomédicale, Sorbonne University, Paris, Île-de-France, France

${ }^{25}$ Service de Médecine Interne et Centre National de Référence Maladies Systémiques Rares, University Hospital Pitié Salpêtrière, Paris, Île-de-France, France

Acknowledgements The authors would like to thank Dr MD Diebold, L Samaison, Mestdagh, J Keraen and L Genser for sending samples or clinical information, as well as M Bakari, R Ben Jannet, GC Kotokpo Youkou, N Terrones for expert technical assistance. The work was supported in part by unrestricted grants from Association pour la Recherche et l'Enseignement en Pathologie (AREP).
Contributors FC-A prepared the original manuscript draft and was in charge with the clinical analysis of the cases. IU prepared the original manuscript draft and was in charge with the histopathological analysis of the cases. JR handled clinical data collection and data analysis. FC was in charge with histopathology analysis. SV-D handled data collection and data analysis. ZH-R handled the interpretation of molecular tests. DC-H handled histopathological data collection and analysis. PD handled histopathological data collection and analysis. MD-C handled histopathological data collection and analysis. JS handled histopathological data collection and analysis. PT handled histopathological data collection and analysis. SH handled clinical data collection and data analysis. AM handled data collection and data analysis related to radiology. MK provided clinical data. LV handled histopathological data collection and analysis. CP handled clinical data collection and data analysis. AS handled clinical data collection and data analysis. AT handled data collection and data analysis. JD handled data collection and data analysis. $\mathrm{OL}$ handled data collection and data analysis related to radiology. $\mathrm{JH}$ designed and conducted the study, prepared the original manuscript draft and was in charge with the clinical analysis of the cases. J-FE designed and conducted the study, prepared the original manuscript draft and was in charge with the pathology and molecular analysis of the cases. All the authors corrected and approved the final version of the manuscript.

Funding Work funded in part by Association Pour la Recherche et L'enseignement en Pathologie.

Competing interests None declared.

Patient consent for publication Obtained.

Ethics approval The study was approved by the Ethics Committee Île-de-France III (\#2011-A00447-34) and was conducted in accordance with the Declaration of Helsinki.

Provenance and peer review Not commissioned; externally peer reviewed.

Data availability statement Data are available on reasonable request. All data relevant to the study are included in the article or uploaded as supplementary information. Data requests should be addressed to J-FE, MD, PhD at the following mail: jean-francois.emile@uvsq.fr.

Supplemental material This content has been supplied by the author(s). It has not been vetted by BMJ Publishing Group Limited (BMJ) and may not have been peer-reviewed. Any opinions or recommendations discussed are solely those of the author(s) and are not endorsed by BMJ. BMJ disclaims all liability and responsibility arising from any reliance placed on the content. Where the content includes any translated material, BMJ does not warrant the accuracy and reliability of the translations (including but not limited to local regulations, clinical guidelines, terminology, drug names and drug dosages), and is not responsible for any error and/or omissions arising from translation and adaptation or otherwise.

Open access This is an open access article distributed in accordance with the Creative Commons Attribution Non Commercial (CC BY-NC 4.0) license, which permits others to distribute, remix, adapt, build upon this work non-commercially, and license their derivative works on different terms, provided the original work is properly cited, appropriate credit is given, any changes made indicated, and the use is non-commercial. See: http://creativecommons.org/licenses/by-nc/4.0/.

\section{ORCID iDs}

Fleur Cohen-Aubart http://orcid.org/0000-0002-7610-4995

Jerome Razanamahery http://orcid.org/0000-0001-8453-7224

Jean-François Emile http://orcid.org/0000-0002-6073-4466

\section{REFERENCES}

1 Emory TS, Monihan JM, Carr NJ, et al. Sclerosing mesenteritis, mesenteric panniculitis and mesenteric lipodystrophy: a single entity? Am J Surg Pathol 1997;21:392-8.

2 Moore FO, Berne JD, Fox AD. Mesenteric panniculitis and ErdheimChester disease: xanthogranulomatous diseases confused with malignancy. J Am Coll Surg 2007;204:326-7.

3 Alexiou J, Klastersky J. Erdheim-Chester disease: a case report. Am J Case Rep 2015;16:361-6.

4 Balasubramanian G, Modiri A, Affi M, et al. A fatal case of ErdheimChester disease with hepatic involvement. ACG Case Rep J 2017;4:e95

5 Wang $\mathrm{F}$, Cao X, Niu N, et al. Multisystemic imaging findings in Chinese patients with Erdheim-Chester disease. AJR Am J Roentgenol 2019;213:1179-86. 
6 Hassani J, Porubsky C, Berman C, et al. Intraperitoneal RosaiDorfman disease associated with clear cell sarcoma: first case report. Pathology 2016;48:742-4.

7 Alruwaii Zl, Zhang Y, Larman T, et al. Rosai-Dorfman disease of the digestive System-Beware vasculopathy: a clinicopathologic analysis. Am J Surg Pathol 2019;43:1644-52.

8 Dhillon N, Skinnider B, Darabian S, et al. Histiocytosis masquerading in the mesentery and pleura. BMJ Case Rep 2019;12:e232165.

9 Westenend PJ, Akkers RC, Katier N, et al. Erdheim Chester disease presenting as sclerosing mesenteritis. J Hematop 2021;14:87-8.

10 Pickhardt PJ, Bhalla S. Unusual nonneoplastic peritoneal and subperitoneal conditions: CT findings. Radiographics 2005;25:719-30

11 Goyal G, Heaney ML, Collin M, et al. Erdheim-Chester disease: consensus recommendations for evaluation, diagnosis, and treatment in the molecular era. Blood 2020;135:1929-45.

12 Emile J-F, Abla O, Fraitag S, et al. Revised classification of histiocytoses and neoplasms of the macrophage-dendritic cell lineages. Blood 2016;127:2672-81.

13 Colomba E, Hélias-Rodzewicz Z, Von Deimling A, et al. Detection of BRAF p.V600E mutations in melanomas: comparison of four methods argues for sequential use of immunohistochemistry and pyrosequencing. J Mol Diagn 2013;15:94-100.

14 Emile J-F, Diamond EL, Hélias-Rodzewicz Z, et al. Recurrent RAS and PIK3CA mutations in Erdheim-Chester disease. Blood 2014;124:3016-9.

15 Bonnet P, Chasset F, Moguelet P, et al. Erdheim-Chester disease associated with chronic myelomonocytic leukemia harboring the same clonal mutation. Haematologica 2019;104:e530-3.

16 Cohen-Aubart F, Emile J-F, Carrat F, et al. Phenotypes and survival in Erdheim-Chester disease: results from a 165-patient cohort. Am J Hematol 2018;93:E114-7.
17 Tran TAN, Chang KTE, Kuick CH, et al. Local ALK-Positive Histiocytosis With Unusual Morphology and Novel TRIM33-ALK Gene Fusion. Int J Surg Pathol 2020:106689692097686.

18 Garc-ia JF, Sánchez E, Lloret E, et al. Crystal-storing histiocytosis and immunocytoma associated with multifocal fibrosclerosis. Histopathology 1998;33:459-64.

19 Aline-Fardin A, Bender S, Fabiani B, et al. Pseudo-Peritoneal carcinomatosis presentation of a Crystal-Storing histiocytosis with an Unmutated monoclonal $\kappa$ light chain. Medicine 2015;94:e1247.

20 Yang S, Wang L, Sun K. Ovarian mucinous cystic tumor associated with sarcomatous mural nodule and benign Brenner tumor: a case report and literature review. Medicine 2019;98:e14066.

21 Durham BH, Lopez Rodrigo E, Picarsic J, et al. Activating mutations in CSF1R and additional receptor tyrosine kinases in histiocytic neoplasms. Nat Med 2019;25:1839-42.

22 Sharma P, Yadav S, Needham CM, et al. Sclerosing mesenteritis: a systematic review of 192 cases. Clin J Gastroenterol 2017;10:103-11.

23 Akram S, Pardi DS, Schaffner JA, et al. Sclerosing mesenteritis: clinical features, treatment, and outcome in ninety-two patients. Clin Gastroenterol Hepatol 2007;5:589-96.

24 Danford CJ, Lin SC, Wolf JL. Sclerosing mesenteritis. Am J Gastroenterol 2019;114:867-73.

25 Henrard S, Corbière V, Schandené L, et al. Proportions of interferon- $\gamma$-producing ascites lymphocytes in response to mycobacterial antigens: a help for early diagnosis of peritoneal tuberculosis in a low TB incidence country. PLoS One 2019;14:e0214333.

26 Nikpanah M, Kim L, Mirmomen SM, et al. Abdominal involvement in Erdheim-Chester disease (ECD): MRI and CT imaging findings and their association with BRAF ${ }^{\mathrm{V} 600 \mathrm{E}}$ mutation. Eur Radiol 2018;28:3751-9. 